\title{
DESKRIPSI INTENSITAS SUARA PADA UNIT RAW MILL PT. HOLCIM INDONESIA Tbk. CILACAP
}

\author{
Bangun Adhi Gunawan"),Marsum ${ }^{2)}$ \\ Jurusan Kesehatan Lingkungan, Politeknik Kesehatan Kemenkes Semarang, \\ Jl.Raya Baturaden KM 12 Purwokerto, Indonesia
}

\begin{abstract}
Abstrak
Menurut teori H.L Blum, salah satu parameter kualitas lingkungan yang perlu diawasi adalah bising. Unit Raw Mill merupakan salah satu unit dalam proses pembuatan semen yang bertujuan untuk menghancurkan dan mencampur bahan baku agar terhomogenisasi dengan cara proses penggilingan menggunakan mesin yang menghasilkan suara yang tidak dikehendaki oleh pekerja PT. Holcim. Oleh karena itu, peneliti ingin mengetahui intensitas suara pada Unit Raw Mill PT. Holcim Indonesia Tbk. Cilacap Plant 2015.Metode peneltian yang digunakan yaitu dengan menganalisis secara deskriptif, yaitu menggambarkan tentang kondisi yang sesungguhnya sesuai data yang diperoleh dalam pengukuran intensitas suara pada Unit Raw Mill PT. Holcim Indonesia Tbk Cilacap Plant. Hasil pengukuran intensitas suara pada Unit Raw Mill adalah titik I 96,49 dB, titik II 93,24 dB, titik III 91,29 dB, titik IV 83,89 dB dan titik V 81,15. Jenis alat pelindung diridan alat pelindung keselamatan yang digunakan pekerja di Unit Raw Mill adalah earplug, helmet, rompi, googles, kacamata, safety glass dan masker. Keluhan yang dirasakan adalah keluhan pekerja yang mengalami tuli adalah $0 \%$, sulit berkomunikasi $100 \%$, kurang konsentrasi $70 \%$, gangguan tidur $40 \%$ dan telinga berdengung $80 \%$. Hasil tersebut diperoleh dengan cara wawancara dari 10 responden di Unit Raw Mill. Berdasarkan hasil tersebut dapat disimpulkan bahwa rata-rata intensitas suara Unit Raw Mill tergolong tinggi dan melebihi NAB kebisingan untuk waktu kerja selama 8 jam.
\end{abstract}

Kata kunci : Intensitas suara,, kesehatan lingkungan

\begin{abstract}
According to the theory HL Blum, one of the environmental quality parameters that need to be monitored is noisy. Unit Raw Mill is one of the units in the cement manufacturing process that aims to crush and mix the raw materials so homogenized by means of a milling process using a machine that produces sound that is not desired by the workers of PT. Holcim. Therefore, researchers wanted to determine the intensity of the sound at Raw Mill Unit PT. Holcim Indonesia Tbk. Cilacap Plant 2015. The method used is by analyzing the descriptive, which describe the actual condition according to the data obtained in the measurement of sound intensity at Raw Mill Unit PT. Holcim Indonesia Tbk Cilacap Plant. Results of sound intensity measurement in Unit Raw Mill is the point I 96.49 dB, 93.24 dB point II, point III $91.29 \mathrm{~dB}, 83.89 \mathrm{~dB}$ point and point IV V 81.15. The type of personal protective equipment and safety protective equipment used in Unit Raw Mill workers are earplugs, helmets, vests, goggles, sunglasses, safety glasses and masks. Perceived complaints are complaints of workers who are deaf is $0 \%$, it is difficult to communicate 100\%, 70\% lack of concentration, sleep disorders and ear buzzing 40\% to $80 \%$. The results obtained by interview of 10 respondents in Unit Raw Mill. Based on these results it can be concluded that the average intensity of sound Unit Raw Mill is high and exceeds the noise NAB to working time for 8 hours.
\end{abstract}

Keywords : intensity of sound, environmental health

\section{PENDAHULUAN}

Industrialisasi merupakan motor penggerak bagi peningkatan kemakmuran dan menempati posisi sentral dalam kehidupan masyarakat modern terutama di negara maju. Di negara berkembang, industri sangat esensial untuk memperluas landasan pembangunan dan memenuhi kebutuhan masyarakat (Kristanto P, 2002).

Adanya industrialisasi terjadi peningkatan kesejahteraan penduduk, hal ini dapat dilihat dengan pertumbuhan penduduk dunia yang semakin pesat.Dengan adanya teknologi/ mesin-mesin yang semakin modern, meringankan dan mempermudah manusia dalam memenuhi kebutuhannya. Namun di sisi lain, bila tidak dikelola dengan baik maka menimbulkan dampak yang membahayakan manusia antara lain keselamatan jiwa, kecacatan, penurunan kualitas lingkungan, penurunan derajat kesehatan dan kerugian ekonomi. Keuntungan besar yang didapat dari kegiatan industri, apabila tidak dikelola dengan memperhatikan keseimbangan lingkungan maka keuntungan sering kali lebih sedikit bila dibandingkan biaya sosial yang dikeluarkan untuk mengatasi dampak negatif. Kerugian sosial ini 
sebagian besar merupakan kerugian yang ditimbulkan pada lingkungan, karena lingkungan sebagai penopang kehidupan generasi sekarang dan generasi penerus. Bila lingkungan rusak, efek negatif yang ditimbulkan tidak hanya dirasakan oleh generasi sekarang, tetapi juga dirasakan generasi mendatang bahkan efek ke generasi

Indonesia masih menempati urutan keempat negara dengan jumlah penderita gangguan pendengaran di Asia. Jakarta adalah kota dengan tingkat kebisingan mencapai 90 desibel, 20 desibel diatas normal. Lebih dari 1 jam terpapar normal kebisingan pada tingkat ini sangat berbahaya bagi pendengaran. Kebisingan menjadi kehidupan seharihari masyarakat di kota besar di Indonesia. Padahal lama-lama kebisingan akan menjadi penyebab gangguan pendengaran. Tak mengherankan kalau indonesia masuk negara dengan kasus pendengaran di Asia. Menurut Damayanti Soetjipto, pendiri Komite Nasional Penanggulangan Gangguan dan Ketulian, 4,6\% penderita pendengaran di Asia berasal dari Indonesia.

Penelitian yang pernah dilakukan oleh Jennie Babba (2007) tentang hubungan antara intensitas kebisingan di lingkungan dengan tekanan darah pekerja PT. Semen Tonasa di Kabupaten Pangkep Sulawesi Selatan menunjukan hasil bahwa tempat hubungan yang signifikan antara intensitas kebisingan di lingkungan dengan peningkatan tekanan darah sistolik ( $\mathrm{p}=0,000, \mathrm{PR}=10,5 ; 95 \%$ CI$1,63)$ dan tekanan darah diastolik $(\mathrm{p}=0,001 ; \mathrm{PR}=7,6$; 95\% CI-1,17). Penelitian yang dilakukan tersebut menunjukkan bahwa kebisingan terbukti menyebabkan dampak kesehatan selain merusak indra pendengaran juga meningkatkan tekanan darah pada pekerja.

PT. Holcim Indonesia Tbk merupakan salah satu perusahaan yang memproduksi semen.PT Holcim Tbk mengoperasian dua pabrik yaitu di Narogong, Jawa Barat dan di Cilacap, Jawa Tengah serta satu stasiun penggilingan di Ciwandan, Banten. Kapasitas produksi tahunan ini adalah 8,3 juta ton dengan adanya Pabrik Tuban, kapasitas menjadi 10 juta ton pada tahun 2014.

PT. Holcim Indonesia Tbk Cilacap memproduksi semen serbaguna (General Use Cement). Bahan baku pembuatan semen adalah batu kapur (limestone), tanah liat (clay), pasir besi (iron sand), pasir silica (silica sand) dan gypsum. Batu kapur diperoleh dari penambangan di Pulau Nusa Kambangan, tanah liat diperoleh dari penambangan di Jeruk Legi, pasir besi diperoleh dari PT. Aneka Tambang yang mempunyai wilayah penambangan disepanjang pantai Cilacap sampai Yogyakarta, pasir silika dari Jatirogo, Jawa Timur dan Cibadak, Jawa Barat dan gypsum diperoleh dari PT. Petrokimia Gresik. Adapun proses yang digunakkan adalah proses kering (dry process) dengan tahapan-tahapan proses yaitu : penyediaan bahan baku, penggilingan bahan baku, pembakaran bahan baku (raw meal), pendinginkan clinker, penggilingan akhir serta pengantongan semen.

Alat-alat utama yang digunakan adalah raw mill, homogenezing silo, rotarykiln dan finish mill (cement mill). Sedangkan alat-alat pendukungnya berupa electrostatic precipator, bag filter dan berbagai transport seperti belt conveyor, bucket elevator, screw conveyor, dan drag chain conveyor.Proses-proses tersebut semua menggunakan mesin yang berkapasitas besar dan juga menghasilkan suara yang tidak dikehendaki oleh pengelola maupun pekerja. Menurut hasil wawancara dengan OHS (Occupational Health Safety) PT. Holcim Indonesia Tbk Cilacap Plant, intensitas suara unit Raw Mill yaitu berkisar antara 80-90 dB.

Unit Raw Mill merupakan salah satu unit dalam proses pembuatan semen yang bertujuan untuk menghancurkan dan mencampur bahan baku agar terhomogenisasi dengan cara proses penggilingan ini menggunakan mesin yang menghasilkan suara yang tidak dikehendaki oleh pemilik PT. Holcim maupun oleh pekerja dan juga masyarakat sekitar. Suara yang dihasilkan ini terpaksa mereka dengar agar proses produksi terus berjalan. Suara tersebut berasal dari 2 ruangan Compressor dan 1 unit mesin penggiling (mesin Raw Mill).Berdasarkan hal tersebut peneliti mencoba mengadakan penelitian dengan judulDeskripsi Intensitas Suara Pada Unit Raw Mill PT. Holcim Indonesia Tbk Cilacap Plant Tahun 2015.

\section{METODE}

Jenis peneltian yang digunakan yaitu dengan menganalisis secara deskriptif, yaitu menggambarkan tentang kondisi yang sesungguhnya sesuai data yang diperoleh dalam pengukuran intensitas suara pada Unit Raw Mill PT. Holcim Indonesia Tbk Cilacap Plant.Raw Mill Table merupakan penghasil sumber bising paling tinggi Mesin Compressor merupakan mesin yang menjalankan mesin-mesin Raw Mill, oleh sebab itu dilakukan pengukuran didekat mesin tersebut.Pengukuran pada jarak 1 meter dari mesin Raw Mill dilakukan karena pekerja kontraktor sering memnbersihkan material-material bahan baku.

\section{III.HASIL DAN PEMBAHASAN}

Berdasarkan hasil pengukuran Intensitas suara pada Unit Raw Mill di Unit Raw Mill PT. Holcim Indonesia Tbk. Cilacap Plant selama 2 kali pengukuran pada tanggal 15 April 2015 diketahui bahwa :

1. Rata-rata intensitas suara pada Unit Raw Millyang diukur 1 meter dari Table Raw Mill adalah 96.49 $\mathrm{dB}$ dapat dikategorikan sudah melebihi NAB dan dianalisis dari kegiatan yang dilakukan pada titik tersebut pada kegiatan patrol terhadap mesin Raw Mill dan pembersihan area sekitar Raw Mill yang dilakukan selama kurang lebih 2 jam/shift. Berdasarkan Permenaker No. 13 tahun 2011 dan Kepmenkes No. 1405 tahun 2002 yang mengatur Nilai Ambang Batas (NAB), untuk lama paparan 
dengan sumber bising selama 2 jam NAB kebisingannya adalah $91 \mathrm{~dB}$. Buchari (2007) mengelompokan jenis kebisingan ini adalah kebisingan yang merusak (Damaging/ injorious noise) adalah bunyi yang melampaui NAB. Bunyi jenis ini akan merusak fungsi pendengaran.

2. Rata-rata intensitas suara pada Unit Raw Mill yang diukur pada jarak 5 meter dari mesin Raw Mill dan 1 meter dari mesin compressor luar adalah 93,24 dB yang masih dikategorikan dibawah NAB dianalisis berdasarkan kegiatan yang dilakukan pada titik tersebut yaitu pengaturan panel listrik serta pengecekan compressor yang dilakukan kurang lebih 1 jam/shift. Berdasarkan Permenaker No. 13 Tahun 2011 dan Kepmenkes No. 1405 Tahun 2002 yang mengatur Nilai Ambang Batas (NAB) kebisingan, untuk lama paparan dengan sumber bising selama 1 jam NAB kebisingannya adalah $94 \mathrm{~dB}$ pada lingkungan perkantoran dan industri. Suma'mur (2009) juga mengklasifikasikan intensitas suara yang besarnya mencapai $90 \mathrm{~dB}$ dapat dikatakan kondisi tersebut sangat hiruk piruk yang berjenis kebisingan menetap berkelanjutan tanpa putusputus dengan spectrum frekuensi lebar. Upaya yang dilakukan agar pekerja tidak mendapat resiko gangguan yang diakibatkan kebisingan tersebut adalah merawat atau mesin yang digunakan seperti pelumasan pada bagian yang bergerak mengatur jadwal kerja, pemeriksaan kesehatan secara rutin setiap tahunnya dan pekerja menggunakan alat penyumbat dan pelindung telinga serta mengatur jadwal kerja sehingga bukan pekerja tertentu saja yang beresiko tinggi tersebut.

3. Rata-rata intensitas suara pada Unit Raw Mill yang diukur 10 meter dari Table Raw Mill adalah 91,29 dB dapat dikategorikan sudah melebihi NAB dan dianalisis dari kegiatan yang dilakukan pada titik tersebut pada kegiatan patrol terhadap mesin Raw Mill dan pembersihan area sekitar Raw Mill yang dilakukan selama kurang lebih 2 jam/shift. Berdasarkan Permenaker No. 13 tahun 2011 dan Kepmenkes No. 1405 tahun 2002 yang mengatur Nilai Ambang Batas (NAB), untuk lama paparan dengan sumber bising selama 2 jam NAB kebisingannya adalah $91 \mathrm{~dB}$. Heru dan Haryono (2007) menggolongkan kebisingan tersebut sebagai bising industri berdasarkan sumber bisingnya. Bising industri dapat dirasakan oleh karyawan. Agar kebisingan tersebut tidak berdampak negatif terhadap karyawan PT. Holcim Indonesia Tbk Cilacap Plant dan pekerja kontraktor, maka perlu dilakukan upaya pengendalian pada sumber bising dapat dilakukan dengan cara :

a. Mengatur tempat sumber

b. Mengatur waktu operasi mesin

4. Rata-rata intensitas suara pada Unit Raw Mill yang diukur pada Ruang Compressor Barat adalah 83,89 $\mathrm{dB}$ dapat dikategorikan tidak melebihi NAB dan dianalisis dari kegiatan yang dilakukan pada titik tersebut pada kegiatan patrol terhadap mesin Compressor yang berada didalam ruangan dan pengecekan sekitar Raw Mill yang dilakukan selama kurang lebih 30 menit, karena ruang compressor yang tertutup sehingga tidak meimbulkan bising yang tinggi dan tidak terlalu mempengaruhi pekerja patrol.

5. Rata-rata intensitas suara pada Unit Raw Mill yang diukur pada Ruang Compressor Timur adalah $81,15 \mathrm{~dB}$ dapat dikategorikan tidak melebihi NAB dan dianalisis dari kegiatan yang dilakukan pada titik tersebut pada kegiatan patrol terhadap mesin Raw Mill pengecekan area sekitar Raw Mill yang dilakukan selama kurang lebih 30 menit, karena ruang compressor yang tertutup sehingga tidak meimbulkan bising yang tinggi dan tidak berpengaruh pada pekerja patrol.

Lama paparan pekerja dengan sumber bising yang terdapat pada Unit Raw Mill PT. Holcim Indonesia Tbk. Cilacap Plant adalah berdasarkan jenis pekerjaan. Setiap jenis pekerjaan adalah berbedabeda akan tetapi waktu setiap pekerja adalah sama yaitu 8 jam/hari dalam 1 shift. Ada beberapa jenis pekerjaan yaitu SI, OJT SI, panel, plant patrol, operator reclaimer clay, operator reclaimer silica sand, operator reclaimer iron sand, operator limestone dan cleaning area Raw Mill adalah sebagai berikut :

1. Jenis pekerjaan sebagai $S I$ dan $O J T S I$, lama paparandari sumber bising adalah kurang lebih 1 jam. Jenis pekerjaan ini lebih sering di kantor yang letaknya jauh dari sumber bising dari Unit Raw Mill kurang lebih 100 meter

2. Jenis pekerjaan patrol plant dan panel, lama paparan dari sumber bising adalah kurang lebih 3$4 \mathrm{jam} / \mathrm{shift}$, setelah pekerjaanya selesai mereka langsung kembali ke basecamp, sedangkan untuk pekerja patrol juga memasuki Ruang Compressor barat dan Ruang Compressor timur selama kurang lebih 30 menit dan tidak melebihi NAB yang ditentukan.

3. Jenis pekerjaan operator reclaimer clay, operator reclaimer limestone, operator reclaimer pasir iron sand, operator silica sand dan cleaning, lama paparan dari sumber bising adalah kurang lebih 68 jam/shift. Setelah pekerjaan selesai ada jam istirahat atau kembali ke basecamp.

Hasil tabel wawancara tentang keluhan yang dirasakan oleh pekerja pada unit Raw Mill terhadap 10 responden dapat disimpulkan sebagai berikut :

1. Keluhan sulit berkomunikasi pada saat bekerja di Unit Raw Mill sebanyak $100 \%$. Budiman Chandra (2006) menjelaskan resiko potensial pada pendengaran terjadi apabila komunikasi dengan pembicaraan harus dengan cara berteriak. Gangguan macam itu dapat menyebabkan gangguan pekerjaan bahkan mengakibatkan 
kesalahan dan kecelakaan kerja terutama pada pekerja baru. Hal ini dapat dibantu dengan walky talky.

2. Telinga sering berdengung sebanyak $80 \%$ telinga yang sering berdengung dapat menyebabkan ketulian. Hal ini terjadi akibat penggunaan alat pelindung telinga yang kurang pas. Kondisi telinga yang sering berdengung dapat mengakibatkan gangguan pendengaran, upaya yang harus dilakukan adalah pemeriksaan kesehatan secara rutin khususnya pemeriksaan audiometri.

3. Berkurangnya konsentrasi pada pekerja $70 \%$. Menurut Budiman Chandra (2006) kebisingan dapat mengganggu konsentrasi pekerja pada pekerjaanya, terutama suara yang bernada tinggi, karena dapat menimbulkan reaksi psikologis dan kelelahan, sehingga dapat menyebabkan kesalahan dalam bekerja. Pada pekerjaan yang lebih menggunakan otak, kebisingan sebaiknya ditekan serendah mungkin dengan upaya perawatan mesin secara rutin, pengaturan rotasi kerja dan waktu istirahat, serta penggunaan alat pelindung telinga seperti earplug.

4. Gangguan tidur sebanyak $40 \%$.

5. Keluhan yang dirasakan tuli sebanyak $0 \%$. Artinya tidak ada, sehingga pekerja yang bekerja di Unit Raw Mill dikatakan sehat.

Unit Raw Mill merupakan unit yang bising dengan kebisingan di atas NAB untuk waktu paparan 1 shift kerja atau 8 jam, oleh karena itu pekerja dan orang yang memasuki Unit Raw Mill diharuskan menggunakan earmuff dan earplug. Buchari (2007) menjelaskan bahwa sumbat telinga (earplug) dapat menurunkan kebisingan 8-30 dB dan tutup telinga (earmuff) dapat menurunkan kebisingan 25-40 dB. Pekerja yang menggunakan alat pelindung telinga akan merasa lebih aman dan tidak terganggu dengan suara bising yang ada di Unit Raw Mill.

PT. Holcim Indonesia Tbk Cilacap Plant bekerja sama dengan perusahaan kontraktor dalam menyediakan alat pelindung diri termasuk alat pelindung telinga untuk para pekerja. Alat pelindung telinga yang disediakan perusahaan adalah earplug dan earmuff. Selain itu perusahaan juga menyediakan alat pellindung diri lainya seperti masker, safety shoes, sarung tangan, google atau safety glass, helmet dan alat keselamatan yang digunakan adalah rompi. Penggunaan alat pelindung telinga di Unit Raw Mill sudah diterapkan dengan baik, karena pengawasan safety officer yang ketat.

Upaya pengendalian bahaya yang dilakukan oleh PT. Holcim Indonesia Tbk Cilacap Plant adalah berprinsip HIRARC yaitu eliminasi, subtitusi, teknis, administrasi dan APD.Pada Unit Raw Mill upaya eliminasi dan subtitusi tidak dilakukan. Upaya-upaya yang dilakukan adalah sebagai berikut :

1. Upaya pengendalian secara teknis
Upaya pengendalian kebisingan secara teknis yang dilakukan oleh PT. Holcim Indonesia Tbk. Cilacap Plant khususnya pada Unit Raw Mill adalah dilakukan perawatan, pengecekan dan perbaikan secara rutin. Perawatan dan perbaikan mesin secara rutin setiap 1 tahun sekali atau yang disebut "overhaul" yang berupa pembersihan mesin secara keseluruhan dan pelumasan pada mesin penggiling, sedangkan perawatan dan perbaikan mesin dilakukan secara tiba-tiba dan dilakukan pengecekan mesin oleh kegiatan patrol para pekerja yang berupa perbaikan panel maupun pemberhentian karena blending silo sudah penuh material. Selain itu, upaya juga dilakukan penanaman pohon dengan jenis pohon pinus dan juga beraneka macam pohon buah-buahan seluas 4,5 ha disekitar pabrik serta peninggian tembok mesin setinggi 25 meter. Upaya pengendalian kebisingan secara teknis yang telah dilakukan oleh PT. Holcim Indonesia Tbk Cilacap Plant khususnya pada Unit Raw Mill sudah sesuai dengan teori Soehatman Ramli (Seri Manajemen K3 02，2010， h.104) OHSAS 18001 yang memberikan pedoman pengendalian resiko yang telah spesifik untuk bahaya K3 di perusahaan serta tata cara pada Kepmenkes No. 1405 tahun 2002 tentang persyaratan kesehatan dan keselamatan lingkungan kerja perkantoran dan industri. Upaya yang sudah dilakukan dapat dipertahankan dan juga ditingkatkan agar kesehatan dan keselamatan kerja lebih terjamin.

2. Upaya pengendalian secara administrasi

Upaya pengendalian kebisingan secara administrasi yang dilakukan oleh PT. Holcim Indonesia tbk Cilacap Plant khususnya pada Unit Raw Mill adalah :

a. Dilakukanya pembagian jam kerja/ shift kerja yang menggunakan 3 shift kerja dan 1 shift libur. Pembagian shift kerja berdasarkan jadwal rotasi kerja yang diatur setiap bulan dan 3 hari sekali pekerja dapat libur dan hari selanjutnya berganti shift kerja.

b. Pengaturan jam istirahat dilakukan setelah pekerja melakukan stengah shift kerja. PT. Holcim Indonesia Tbk Cilacap Plant juga bekerja sama dengan jasa boga cathering untuk melayani kantin bagi karyawan PT. Holcim Indonesia Tbk Cilacap Plant.

c. Adanya Standar Operasional Prosedur (SOP) pekerjaan yang berbeda-beda disetiap area. Semua pekerja yang bekerja sudah bekerja sesuai prosedur yang ada.

d. Pemeriksaan kesehatan karyawan dan pekerja kontraktor setiap 1 tahun sekali dan juga layanan jaminan kesehatan. Pemeriksan kesehatan dilakukan untuk mengetahui paparan apa saja yang diterima saat bekerja. Pemeriksaan pekerja dilakukan saat penerimaan pekerja agar pekerja diharapkan benar-benar sehat. 
e. Kebijakan dalam mewajibkan dalam penggunaan APD secara lengkap apabila memasuki area produksi yang berupa slogan atau tanda bahaya dan juga petunjuk keamanan. Dengan adanya tanda, slogan dan petunjuk keamanan, maka pekerja atau orang yang ada didaerah tersebut dapat mengetahui ada tidaknya bahaya. Tanda yang terpasang yaitu penggunaan APD spesifik, jalur evakuasi, listrik tegangan tinggi, slogan, kebisingan tinggi dan ketentuan K3. Kebijakan penggunaan APD secara lengkap tidak hanya berlaku pada karyawan dan pekerja kontraktor, tetapi mahasiswa dan tamu yang sedang melakukan praktik kerja maupun kunjungan wajib menggunakan APD.

f. Training untuk pekerja baru serta dilakukannya induksi untuk setiap pekerja baru maupun mahasiswa yang akan melakukan praktek kerja. Training yang dilakukan bertujuan untuk menambah ilmu, informasi pengetahuan dan pengarahan pada pekerja sesuai dengan prosedur sehingga kecelakaan kerja dapat diminimalisir, karena kesehatan dan keselamatan kerja tanggung jawab kita bersama.

g. Upaya ini juga mempunyai efek bagi pekerja yang tidak memenuhi peraturan karena bagi pekerja yang melanggar untuk pertama kalinya akan diperingatkan secara lisan oleh safety officer. Untuk pelanggaran kedua akan diperingatkan secara tertulis dan yang ketiga kalinya pekerja akan mengalami PHK.

3. Penggunaan alat pelindung telinga

Upaya terakhir untuk mengendalikan kebisingan di Unit Raw Milladalah penggunaan alat pelindung telinga.Hal ini disebabkan karena APD seperti alat pelindung telinga bukan untuk mencegah kecelakaan namun hanya sekedar mengurangi keparahan kecelakaan kerja.Unit Raw Mill merupakan unit yang bising dengan kebisingan di atas NAB untuk waktu paparan 1 shift kerja atau 8 jam, oleh karena itu pekerja dan orang yang memasuki Unit Raw Mill diharuskan menggunakan earmuff dan earplug. Buchari (2007) menjelaskan bahwa sumbat telinga (earplug) dapat menurunkan kebisingan 8-30 dB dan tutup telinga (earmuff) dapat menurunkan kebisingan 25-40 dB. Pekerja yang menggunakan alat pelindung telinga akan merasa lebih aman dan tidak terganggu dengan suara bising yang ada di Unit Raw Mill.

PT. Holcim Indonesia Tbk Cilacap Plant bekerja sama dengan perusahaan kontraktor dalam menyediakan alat pelindung diri termasuk alat pelindung telinga untuk para pekerja. Alat pelindung telinga yang disediakan perusahaan adalah earplug dan earmuff.Selain itu perusahaan juga menyediakan alat pellindung diri lainya seperti masker, safety shoes, sarung tangan, google atau safety glass, helmet dan rompi.Penggunaan alat pelindung telinga di Unit Raw Mill sudah diterapkan dengan baik, karena pengawasan safety officer yang ketat.

\section{IV.KESIMPULAN}

1. Rata-rata tingkat Intensitas suara di Unit Raw Mill PT. Holcim Indonesia Tbk. Cilacap Plant dapat diketahui yaitu 81,15 - 96,49 dB.

2. Paparan kerja dengan sumber bising di Unit Raw Mill dilihat dari jenis pekerjaan. Untuk jenis pekerjaan SI dan OJT SI kurang lebih 1 jam, panel patrol adalah 3-4 jam/shift dan untuk patrol juga memasuki Ruang compressor barat dan Ruang compressor timur kurang lebih 30 menit, untuk jenis pekerjaan operator reclaimer clay, operator reclaimer silica sand, operator reclaimer iron sand, operator reclaimer limestone dan cleaning selama 6-8 jam/shift.

3. Keluhan yang dirasakan adalah keluhan pekerja yang mengalami tuli adalah $0 \%$, sulit berkomunikasi $100 \%$, kurang konsentrasi $70 \%$, gangguan tidur $40 \%$ dan telinga berdengung 80 $\%$.

4. Jenis alat pelindung diri yang digunakan pekerja di Unit Raw Mill adalah earplug, helmet, rompi, googles, kacamata, safety glass, safety shoes dan masker

5. Upaya pengendalian yang dilakukan di Unit Raw Mill adalah upaya pengendalian secara teknis yang dilakukan secara rutin setiap tahun, penanaman pohon diarea bising serta peninggian tembok. Upaya pengendalian secara administrasi seperti pembagian shift kerja, pengaturan jam istirahat, pembuatan SOP, wajib bagi pekerja menggunakkan APD dan training bagi pekerja baru.

\section{DAFTAR PUSTAKA}

Ari Susia Dewanti, 2012, Studi Tentang Pengendalian Kecelakaan Kerja Di Unit Finish Mill PT. Holcim Tbk. Cilacap Plant Tahun 2012, Purwokerto : Politeknik Kesehatan kemenkes Semarang.

Dwiyanto B.K, 2007, Hubungan Antara Intensitas Kebisingan di Lingkungan Kerja dengan Peningkatan Tekanan Darah, Semarang Program Pasca Sarjana Magister Kesehatan Lingkungan Universitas Diponegoro Semarang http://eprints.undip.ac.id/17966/1/.pdf pada 24 Desember 2014 pukul 17.12 WIB.

Gorai and Pal, 2006, Hubungan Antara Intensitas Kebisingan di Lingkungan Kerja dengan Peningkatan Tekanan Darah, Semarang Program Pasca Sarjana Magister Kesehatan Lingkungan Universitas Diponegoro 
Semarang

http://eprints.undip.ac.id/17966/1/.pdf pada 24

Desember 2014 pukul 17.12 WIB.

Homenuck, 1988 ,Pengantar Ilmu Lingkungan. Yogyakarta: Penerbitan Universitas Atma Jaya.

Heru dan Haryono, 2008, Hygene Lingkungan Kerja, Yogyakarta: Penerbitan Mitra Cendikia

Hadi, 1995, Kebisingan Industri dan Hearing Program, Medan http://library.usu.ac.id/download/ft/07002729. pdf tanggal 24 Desember 2014 pukul 16.45 WIB.

Jennie Babba 2007, Hubungan Antara Intensitas Kebisingan di Lingkungan Kerja dengan Peningkatan Tekanan Darah, Semarang Program Pasca Sarjana Magister Kesehatan Lingkungan Universitas Diponegoro Semarang at http://eprints.undip.ac.id/17966/1/.pdf pada 24 Desember 2014 pukul 17.12 WIB.

Groothoft, 2003, Hubungan Antara Intensitas Kebisingan di Lingkungan Kerja dengan Peningkatan Tekanan Darah, Semarang Program Pasca Sarjana Magister Kesehatan Lingkungan Universitas Diponegoro Semarang at http://eprints.undip.ac.id/17966/1/.pdfpada 24 Desember 2014 pukul 17.12 WIB.

Harrington dan Gill, 2005, Buku Saku Kesehatan Kerja, Jakarta : EGC.

Kristanto, 2002, Hubungan Antara Intensitas Kebisingan di Lingkungan Kerja dengan Peningkatan Tekanan Darah, Semarang Program Pasca Sarjana Magister Kesehatan Lingkungan Universitas Diponegoro Semarang at http://eprints.undip.ac.id/17966/1/.pdfpada 24 Desember 2014 pukul 17.12 WIB.

Maulidin, 2009, Studi Tentang Kebisingan di Tempat Kerja PT. Sambas Wijaya Desa Penaruban Kecamatan Kaligondang, Kabupaten Purbalingga Tahun 2009, Purwokerto : Politeknik Kesehatan Kemenkes Semarang.

Noni Sofiyanti, 2009, Studi Komparasi Intensitas Kebisingan pada Beberapa Tempat di Terminal Bus Purwokerto Tahun 2009, Purwokerto : Politeknik Kesehatan Kemenkes Semarang.
PT. Holcim Indonesia Tbk. Cialacap Plant, 2015, Daftar Pekerja Unit Raw Mill : Production Department, Manager Raw Mill Area.

PT. Holcim Indonesia Tbk. Cilacap Plant, 2015, HIRARC : Occupational Health Safety Department

PT. Holcim Indonesia Tbk. Cilacap Plant, 2014, Proses Pembuatan Semen : Production Department

Rau. J.G,dan Wooten D. C.1980. Pengelolaan Keselamatan dan Kesehatan Kerja.Yogyakarta: fitramaya

Republik Indonesia Kementerian Lingkungan Hidup NomorKep-48 MENLH/11/1996.

Republik Indonesia Kementerian Tenaga Kerja dan Transmigrasi. 2011. Permenkertrans No. 13/MEN/X/2011 Nilai Ambang Batas Faktor fisika dan Kimia di Tempat Kerja, Jakarta di unggah pada 24 Desember 2014 http://indohse.web.id/ioomia/index.php/refer ensi/doc/ download/20-20nilai-ambang-batasfaktor-fisika-dan-faktor-kimia-di-tempatkerja-nomor:per13menx2011.

Sasongko dan Hardiyarto, 2000, Hubungan Antara Intensitas Kebisingan di Lingkungan Kerja dengan Peningkatan Tekanan Darah, Semarang Program Pasca Sarjana Magister Kesehatan Lingkungan Universitas Diponegoro Semarang at http://eprints.undip.ac.id/17966/1/.pdf pada 24 Desember 2014 pukul 17.12 WIB.

Schomer, 2001, Hubungan Antara Intensitas Kebisingan di Lingkungan Kerja dengan Peningkatan Tekanan Darah, Semarang Program Pasca Sarjana Magister Kesehatan Lingkungan Universitas Diponegoro Semarang at http://eprints.undip.ac.id/17966/1/.pdf pada 24 Desember 2014 pukul 17.12 WIB.

Soeripto, 2008, Kebisingan Industri dan Hearing Program, Medan, Universitas Sumatra Utara.

Suma'mur, 2009, Hubungan Antara Intensitas Kebisingan di Lingkungan Kerja dengan Peningkatan Tekanan Darah, Semarang Program Pasca Sarjana Magister Kesehatan Lingkungan Universitas Diponegoro Semarang at http://eprints.undip.ac.id/17966/1/.pdf pada 24 Desember 2014 pukul 17.12 WIB. 
Suma'mur, 2014, Hygene Perusahaan Dan Kesehatan Kerja, Jakarta : Penerbitan Sagung Seto

Sukmana, 2003,Kebisingan Industri dan Hearing Program, Medan :

http://library.usu.ac.id/download/ft/07002729. pdf tanggal 24 Desember 2014 pukul 16.45 WIB.

Tri Widi Astuti, 2012, StudiTingkat Intensitas Suara dan Upaya Pengendalian Kebisingan di Bagian 50 PT. PERTAMINA (Persero) Refinery Unit (RU) IV Cilacap Tahun 2012, Purwokerto : Politeknik Kesehatan Kemenkes Semarang.
Tri Cahyono, 2012, Pedoman Penulisan Proposal Penelitian dan Karya Tulis Ilmiah, edisi revisi kedua, Purwokerto : Politeknik Kesehatan Kemenkes Semarang Jurusan Kesehatan Lingkungan.

Wall, 1979, Hygene Perusahaan dan Keselamatan Kerja, Jakarta, Erlangga.

WHO (World Health Organization), 1980, Kebisingan Di Tempat Kerja, Jakarta, Universitas Indonesia 